\title{
Publisher's Note: Impact of detector solenoid on the Compact Linear Collider luminosity performance [Phys. Rev. ST Accel. Beams 17, 051002 (2014)]
}

\author{
Y. Inntjore Levinsen, B. Dalena, R. Tomás, and D. Schulte \\ (Received 19 June 2014; published 7 July 2014)
}

DOI: 10.1103/PhysRevSTAB.17.079901

PACS numbers: 29.20.Ej, 29.27.-a, 41.85.Lc, 99.10.Fg

This paper was published online on 27 May 2014 with the wrong image for Fig. 6 . The figure has been restored online as of 19 June 2014.

Published by the American Physical Society under the terms of the Creative Commons Attribution 3.0 License. Further distribution of this work must maintain attribution to the author(s) and the published articles title, journal citation, and DOI. 